\title{
Evidence for nonlinear interactions between atmospheric diurnal tide and 16-day planetary wave in the equatorial meteor winds
}

\author{
Ana Roberta Paulino PIBIC/CNPq/UEPB, Brazil \\ Lourivaldo Mota Lima DF/UEPB, Brazil \\ Paulo Prado Batista INPE, Brazil \\ Copyright 2007, SBGf - Sociedade Brasileira de Geofísica
}

This paper was prepared for presentation at the $10^{\text {th }}$ International Congress of The Brazilian Geophysical Society held in Rio de Janeiro, Brazil, 19-22 November 2007.

Contents of this paper were reviewed by the Technical Committee of the $10^{\text {th }}$ International Congress of the Brazilian Geophysical Society and do not necessarily represent any position of the SBGf, its officers or members. Electronic reproduction, or storage of any part of this paper for commercial purposes without the written consent of the Brazilian Geophysical Society is prohibited.

\begin{abstract}
Zonal and Meridonal wind fields in upper mesosphere and lower thermosphere (MLT) region obtained during 2005 by meteor radar at São João do Cariri-PB, Brazil $\left(7.4^{\circ} \mathrm{S}, 36.5^{\circ} \mathrm{W}\right)$, were used to study the diurnal and planetary waves coupling. The spectral analysis of the hourly winds, besides presenting strong diurnal and semidiurnal power, also shows distinct power spectrum with peaks associated with low-frequency oscillations. Series of amplitudes of the diurnal tides were also obtained. The diurnal tide amplitude series also revealed periodic variability associated with planetary wave occurrence, sometimes with the same periods as the wind amplitudes at the 2, 5, 6.5 and 16-day periods. Here, we investigated the case of the possible coupling between the diurnal tide and 16-day planetary wave, which occurred during autumnwinter period.
\end{abstract}

\section{Introduction}

The atmospheric tides are dominant component of the atmospheric motion in the region of the mesosphere and lower thermosphere (MLT). From numerical and observational studies was verified that tidal amplitudes and phases presents variability in large time scale.

Several mechanisms have been point out to cause atmospheric tide amplitudes variability, such as, changes in the tidal forcing, changes of mean winds and temperature, change in the solar or geomagnetic activity, effect associated with global distribution of ozone, water vapour and the release of latent heat (Beard and Pancheva, 1999).

In the some case it is verified the occur modulation of the amplitudes and phases in periods which are also observed to planetary waves in the winds. The non-linear interaction between atmospheric tides and planetary waves has be proposed for explicate this variability (Beard et al., 1997; Pancheva, 2000; Pancheva and Mukhtarov, 2000). Of the accord with the theory (Spizzichino, 1969; Teitelbaum et al., 1989, Teitelbaum and Vial, 1991), the non-linear interaction between two primary waves generate one family of secondary waves, where this possess generate two waves with frequencies, waves number and phases which results of the addition and difference of the parameter primary waves.

In this work, we investigate the diurnal tide variability at the planetary wave periods and possible nonlinear effects, specifically the coupling between the diurnal tide and 16-day planetary wave, for meteor winds obtained during 2005 at São João do Cariri-PB, Brazil.

\section{Observation and Instrumentation}

The wind data were obtained by the meteor radar which operated at São João do Cariri-PB $\left(7.4^{\circ} \mathrm{S}\right.$, $\left.36.5^{\circ} \mathrm{W}\right)$, in the northeast region of the Brazil. The system, a commercial radar denominated SKiYMET, is an all sky interferometric radar and was designed to operate at very high pulse repetition rates. The system uses an antenna that transmits pulses at 35.24 MHz frequency and five receiver antennae.

In this work, the zonal and meridional winds were estimated in hourly time bins and in seven atmospheric height intervals of $4 \mathrm{~km}$ thickness each, with a height overlap of $0.5 \mathrm{~km}$, centered at 81,84 , $87,90,93,96$ and $99 \mathrm{~km}$. The data were collected from January to December 2005.

\section{Results}

To determine the diurnal tide amplitude variability, the hourly zonal and meridional winds were subjected to harmonic analysis. The analysis was performed for sliding one-day segments stepped by one day. The diurnal tide amplitude and phase of the zonal and meridional wind components in seven atmospheric layers were fitted in a least-meansquare sense, supposing that semidiurnal, diurnal and quasi-2-day oscillations were present in the horizontal wind components at all times, to:

$$
V(t)=V_{\mathrm{o}}+\sum A_{\mathrm{i}} \operatorname{CoS}\left[\left(2 \pi / T_{\mathrm{i}}\right) t-f_{\mathrm{i}}\right]
$$

where $V_{o}, V_{i}$, and $f_{i}$ are the coefficients of the fitting process and represent the prevailing mean, the amplitude, and phase of the ith harmonic component at period of 12,24 , and 48 hours for $i=1,2$, or 3 , respectively. 
Figure 1 presents the time-height cross section of the mean diurnal tide amplitudes for zonal (upper panel) and meridional (bottom panel) components. We note from these plots that diurnal tide amplitudes for meridional component are larger than the zonal component for heights below $96 \mathrm{~km}$ during the year. For heights above $96 \mathrm{~km}$ the zonal and meridional amplitudes generally have the same magnitude. The diurnal tide amplitudes for zonal component maximize for heights above $93 \mathrm{~km}$ reaching velocities larger than $50 \mathrm{~m} / \mathrm{s}$ mainly during JanuaryMarch and during July-August. The amplitude of the diurnal tide for meridional wind component shows maximum amplitudes around $90 \mathrm{~km}$, during February-April and during September-October. Maximum amplitudes are also observed in a region around $96 \mathrm{~km}$, during July-August.
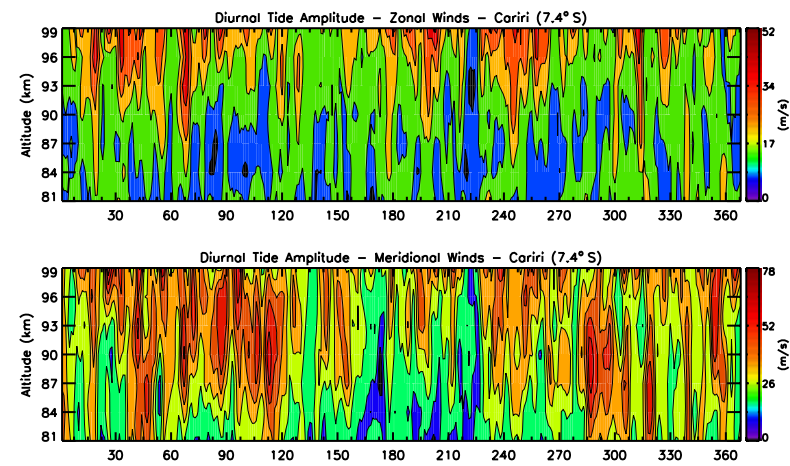

Figure 1 - Time-height cross section of the daily diurnal tide amplitudes obtained by harmonic analysis from zonal (upper panel) and meridional (bottom panel) wind components. The amplitudes have been smoothed with a 3-day running mean.

Since a nonlinear coupling between planetary waves and tides results in an amplitude tide modulations at planetary periods, then the wind and amplitude diurnal tide time series were submitted to spectral analysis by Morlet wavelet transform. In Figure 2 can be seen the results for zonal winds (upper panel) as well as for zonal (middle panel) and meridional (bottom panel) amplitudes of the diurnal tide, for atmospheric layer centred at $90 \mathrm{~km}$. The data were obtained during time interval from day 120 to day 280.

We can identify the presence of the 16 day oscillations as well as diurnal tide in the zonal wind component, during all time considered. Energy associated with periods that fall around 4-8 day and 8-16 days also can be observed.

From the Figure 2 we can see that the amplitudes of the diurnal tide exhibit spectral energy for $\sim 4$ day, $\sim 8$ day and $\sim 16$ day periods.
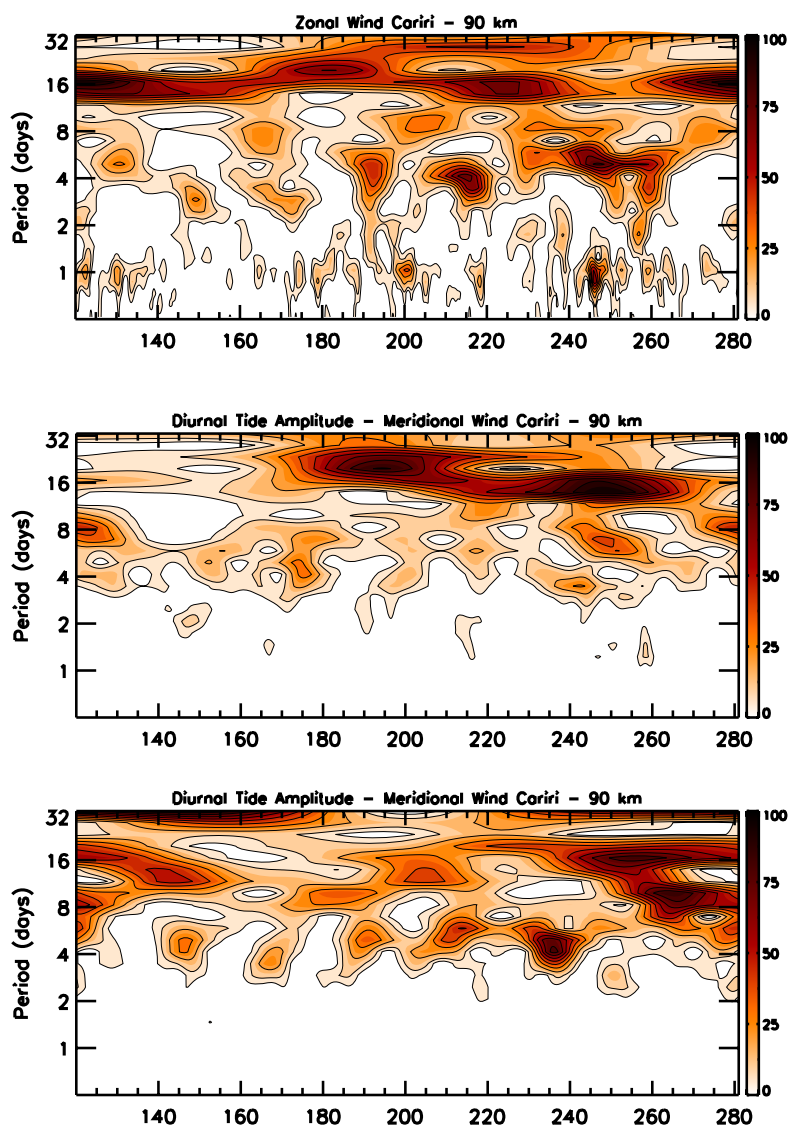

Figure 2 - Morlet wavelet transform spectrum results for the horizontal hourly winds at $90 \mathrm{~km}$ observed during 2005 in the interval from day 120 to day 280 over CaririBrazil. The upper and upper plot represent the spectrum of the zonal winds, whilst the middle and bottom plots represent the spectrum of the diurnal tide amplitudes for zonal and meridonal components, respectively.

To investigate the possible coupling between the 16day wave and the diurnal tide, during the time interval from day 120 to day 280, the Lomb-Scargle periodogram were obtained for 48-day segments stepped by 10 days and the results for winds and for diurnal tide amplitudes of the 180-228 day segment are represented in the Figure 3. Only 0.2-1.6 day and $10-30$ day period intervals are represented and the $95 \%$ confidence level is also indicated by horizontal line in the plots.

Peaks in the 1-day and near 16-day are evident for periodogram of the zonal wind component (upper left plot), which also presents peak near 1.07 day. For periodogram of the meridional wind (upper right plot) component we can see peaks near 0.5 day, 1 day and as well as near 0,86 day, 1,07 day and 1,2 day. In the periodogram of the diurnal tide amplitudes for zonal component (below left plot) appear a strong peak centered near 17 day, whist for meridional component (below right plot) an additional peak appear near 12 day, besides spectral energy around 16 days. 
The nonlinear coupling between 16-day and diurnal tide generate in two secondary waves with periods near 0.94 and 1.07 day. In this case, the presence of the secondary peak near 1.07 day, suggest a nonlinear interaction between 16-day and diurnal tide.
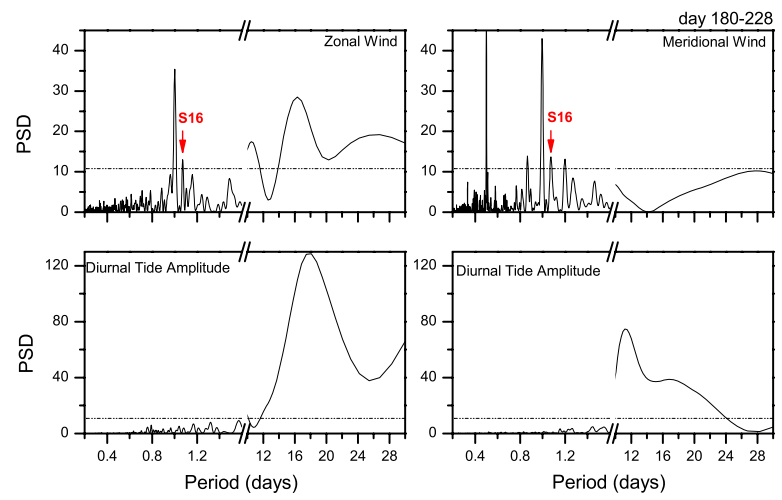

Figure 1 - Lomb-Scargle periodogram for 48-day segment, obtained for winds (upper plots), and for diurnal tide amplitudes (bottom plots). The left side plots and right side plots represents the power spectra density of the zonal and meridional components, respectively. The horizontal line represents the $95 \%$ confidence level.

\section{Conclusion}

Measurements of meteor winds, obtained at São João do Cariri, were used for investigate the relationship between diurnal tide variability and nonlinear coupling between 16 days planetary wave and diurnal tide.

Spectral analysis shown peaks associated with periods near 4-8 day, 8-10 days, and 16 days.

Lomb-Scargle periodogram analysis for interval from day 180 to day 228, shows the presence of additional peaks with periods near 1.07 in the zonal and meridional winds, whereas the diurnal tide amplitudes shows spectral energy that can be associated with 16-day wave modulation during the same time interval.

The presence of the secondary peak near 1.07 day, suggest a nonlinear interaction between 16-day and diurnal tide.

\section{Acknowledgments}

The authors thank to Observatório de Luminescência Atmosférica da Paraíba (OLAP) and Conselho Nacional de Desenvolvimento Científico e Tecnológico (CNPq).

\section{References}

Beard, A. G.; Mitchell, N. J.; Williams, P. J. S.; Kunitake, M. Non-linear interactions between tides and planetary waves resulting in periodic tidal variability. J. Atm. SolarTerrestrial Physics, v.61, n.5, p. 363-376. 1999.

Beard, A. G.; Pancheva, D. A possible cause for the generation of unusually strong $\sim 20$ - and 30-hour oscillations in the neutral wind of the lower thermosphere. J. Atm. and Solar-Terrestrial Physics, v. 61, n. 18, p. 1385-1396, 1999.

Pancheva, D. Evidence for nonlinear coupling of planetary waves and tides in the lower thermosphere over Bulgaria. J. Atm. Solar-Terrestrial Physics, v.62, n.2, p. 115-132. 2000.

Pancheva, D.; Mukhtarov, P. Wavelet analysis on transient behaviour of tidal amplitude fluctuations observed by meteor radar in the lower thermosphere above Bulgaria. An. Geophysicae, v.18, n.3, p. 316-331. 2000.

Spizzichino, A. Étude des interactions entre les différentes composantes du vent dans la haute atmosphère. An. Geophysicae, v.25, n.4, p. 775-771. 1969.

Teitelbaum, H.; Vial, F.; Manson, A. H.; Giraldez, R.; Masseboeuf, M. Non-linear interaction between the diurnal and semidiurnal tides: terdiurnal and diurnal secondary waves. J. Atm. Solar-Terrestrial Physics, v.51, n.7-8, p. 627-634. 1989.

Teitelbaum, H. ; Vial, F. On tidal variability induced by nonlinear interaction with planetary waves. J. Geo. Research, v.96, n.A8, p. 14,169-14,178. 1991. 